\section{THREE VIEWS OF JAPANESE BIOTECH}

Biodudualegy Guide Japen 1990-1991. Nikkei Biotechnology. ISBN 0-93585966-7. \$250, \$95, 591 pages. (Stockton Press, New York: 1990)

Biotechnoley in Japan Yeanbook 1990/1991. Mankets and Re seurch/Drodopment ISBN 0-911501-04-5. \$1200, 916 pages. (Japan Pacific Amocintes, Palo Alto, CA and Nikkei Biotechnology, Tokyo: 1990)

Japane Biotectinalogy. Robert T. Yuan and Mark D. Dibner. ISBN 0-333-531485. \$120, E55, 315 pages. (MacMillan Publimers, Ltd., London: 1990)

A t first thought, it might seem that three books onbiotechnology in Japan are two too many. Not so. These three volumes are as different from each other as East from West.

The first, Biotechnology Guide Japan 19901991, is a bona fide directory of Japanese companies with efforts in biotechnology. This guide is a direct translation of the Japanese directory compiled by Nikkei Biotechnology-if the Japanese edition is accurate in its particulars, it's a safe assumption that this one is, too. Each entry includes a complete description of the company's business, financial data, and the names of its principals. There is also a complete description of R\&cD efforts. Each entry mentions the partners, the objective of the project, its state of development, a description of the product, and its method of production.
The information also includes a list of major relevant patents awarded the company from 1987-1988.

Also translated from Japanese (in this case Nikkei Biotechnology's annual report) is Biotechnology in Japan Yearbook 1990/1991. Markets and Research/Development. This hefty book is worth its weight in yen, and actually complements Biotechnology Guide Japan 1990-1991. This is not a listing of companies. Rather it is an analysis of products and market segments. There is also a section on technology assessment, and special reports on subjects such as agency policies and patents. Those willing to spend the money will find the product-by-product tables useful. An example: the table for granulocyte-colony stimulating factor (G-CSF) reveals that Chugai Pharmaceuticals completed two clinical trials-for bone marrow transplantation and for the granulocytopenia caused by anti-cancer drugs-in 1989. The company is now in a Phase II/III trial for other indications. Kirin Brewery also completed two trials on G-CSF in 1989. And Kyowa Hakko's G-CSF derivative (which is described) is in Phase II.

The authors of Japanese Biotechnology gathered their information during site visits arranged by the American Embassy in Tokyo. In a textbook-like style, the book includes chapters on government policy, universities and research institutes, the Japanese biotechnology industry, technology transfer, finance, and doing business in Japan. If the reader wants specific information on companies or products, however, this is not the book to buy. There are company "capsules" on only ten firms. On the other hand, the descriptions of research at institutes and universities seem to be fairly complete. -Jennifer Van Brunt

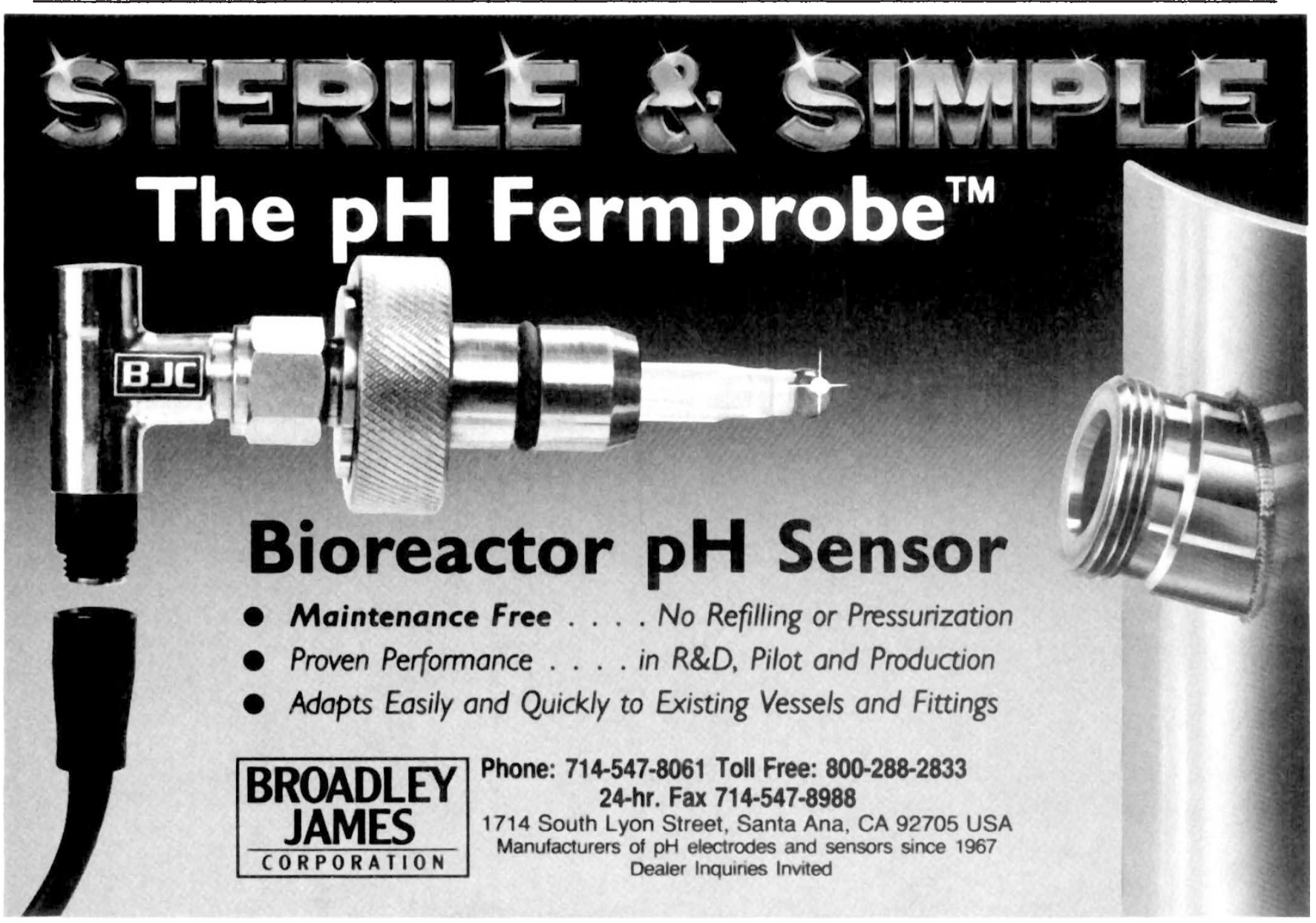

Circle No. 214 on Reader Service Card 